Araştırma ve Geliştirme Dergisi

International Journal of

Engineering Research and

Development
UMAGD, (2021) 13(2), 645-652.

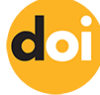

10.29137/umagd.911364

Cilt/Volume:13 Sayı/Issue:2 Haziran/June 2021

Araștırma Makalesi / Research Article

\title{
Aktif Karbon Katkılı Kumaş/Gümüş Nanopartikül Kompozitin Hazırlanması
}

\section{Preparation of Silver Nanoparticle/Activated Carbon-Reinforced Fabric Composite}

\author{
Şule Ocak Araz ${ }^{1}$ iD, Hüseyin Kaya ${ }^{2}$ iD \\ ${ }^{1}$ Kırıkkale Üniversitesi, Mühendislik ve Mimarlık Fakültesi, Metalurji-Malzeme Mühendisliği, 71100, Kırıkkale, TÜRKIYYE \\ ${ }^{2}$ Türk Silahlı Kuvvetleri, MIGYEM Müdürlüğü, 71100, Yahşihan, Kırıkale,TÜRKIYE
}

Başvuru/Received: 07/04/2021

Kabul / Accepted: 29/05/2021

Çevrimiçi Basım / Published Online: 18/06/2021

Son Versiyon/Final Version: 18/06/2021

\section{$\ddot{\mathbf{O z}}$}

Aktif karbon (AC), yüksek yüzey alanı ve gözenekleri sayesinde sıvı ve gaz fazdaki organik ve inorganik maddeleri adsorplama kapasitesi yüksek bir malzemedir. Aktif karbon, savunma sanayinde koruyucu giysi yapımında, silah sanayisinde patlayıcı yapımında ve elektronik sistemleri susturmak için bomba yapımında, gazların ve sıvıların saflaştırılması, arıtılmasında ve sağlık sektörü gibi birçok alanda aktif karbon kullanılır. Bu çalışmada, aktif karbon katkılı kumaşa antimikrobiyal özelliğe sahip Gümüş nanopartiküllerin (AgNP) takviye edilmesi farklı yöntem ve parametrelerinin belirlenerek AC kullanım alanlarının daha da genişletilmesi amaçlanmıştır.

Sulu çözeltide kalloidal olarak oluşan AgNP, Gümüş Nitrat'nn $\left(\mathrm{AgNO}_{3}\right)$ Sodyum Bor hidrür $\left(\mathrm{NaBH}_{4}\right)$ ile kimyasal olarak indirgenmesiyle elde edildi. Sentezlenen AgNP'lerin yapı ve özellikleri UV-VIS spektrofotometresi ve Zeta Potansiyel yöntemleri ile aydınlatıldı. Daha sonra elde edilen AgNP ile Aktif Karbon (AC) katkılı kumaş ultrasonik banyo, manyetik karıştırıcı ve çözelti içinde bekletme gibi farklı yöntemler kullanılarak kumaş üzerine adsorpsiyon yöntemi ile takviye edilmesinde etkin yöntem belirlendi. AgNP/AC katkılı kumaş numunelerinin yüzey yapı analizi Taramalı Elektron Mikroskobu (SEM) ile, yüzeye adsorplanmış gümüş nanopartiküllerin miktarı ise ICP-OES ile belirlendi. Elde edilen verilere göre AC'li kumaşın ultrasonik banyo içerisinde 1 saat bekletilmesiyle AgNP adsorplanması en uygun yöntem olduğu belirlendi.

\section{Anahtar Kelimeler}

"Gümüs Nanopartikül, Aktif Karbon, Adsorplama"

\begin{abstract}
Activated carbon is a materials with high capacity to adsorp organic and inorganic substances in liquid and gaseous phases thanks to its high surface area and pores. In the defense industry, activated carbon is used as protective clothing, in the production of explosives in the weapon industry and in the production of bombs to silence electronic systems, in the distillation and purification of gases and liquids and health sectors. In this study, it was aimed to expand the usage areas of active carbon (AC) by determining different methods and parametres of active carbon doped fabric with having antimicrobial properties of silver nanoparticles (AgNP) reinforcement.

AgNP's formed colloidal in aqueous solution were obtained by chemical reduction of Silver Nitrate $\left(\mathrm{AgNO}_{3}\right)$ with Sodium Borohydride $\left(\mathrm{NaBH}_{4}\right)$. Structure and properties of synthesized AgNP's were illuminated by UV-VIS spectrophotometer and Zeta Potential methods. Then, AC doped fabric with the obtained the AgNP's were covered by using different methods such as ultrasonic bath, magnetic stirrer and soaking in solution and effective coating method was specified. Structure analysis of AgNP/AC composite and the amount of AgNP's adsorbed to the surface were determined with Scanning Electron Microscope (SEM), and ICP-OES respectively. According to the obtained data, it was concluded that the AC fabric is covered with AgNP's are the most approprite method by holding the AC fabric in the ultrasonic bath for 1 hour.
\end{abstract}

Key Words

"Silver Nanoparticle, Activated Carbon, Adsorption" 


\section{Giriş}

Birçok endüstride değişik amaçlar için kullanılan Aktif Karbon (AC); bileşiminin çoğunluğu karbondan oluşan maddelerin fiziksel veya kimyasal olarak aktive edilmesiyle iç yüzey alanı ve gözenek hacmi arttırılmış maddeler olarak tanımlanabilmektedir (Baytar, 2015).

Aktif karbon iç yüzeyinde çok çeşitli molekülleri adsorplayabildiğinden katı veya gaz fazında çeşitli maddelerin adsorpsiyonu için kullanılmaktadır. Gazların saflaştırılması ve içme suyu arıtılmasında, karışımların ayrıştırılmasında, gıda sanayisinde saflaştırma işlemlerinde, atık su arıtımında, metal sanayisinde karbon katkısında, savunma sanayisinde koruyucu giysi yapımında, silah sanayisinde patlayıcı yapımında ve elektronik sistemleri susturmak için bomba yapımında ve sağlık sektöründe olmak üzere çok geniş bir alanda aktif karbon kullanılmaktadır (Küçükgül, 2004).

Hayvanlardan, minerallerden ve sebzelerden elde edilen çeşitli hammaddeler, aktif karbon üretimi için kaynak olabilmektedir (Yahya vd., 2015). Düşük maliyetli, doğal malzemelerden ve bazı tarımsal atık malzemelerden aktif karbon adsorbanlarının geliştirilmesi üzerine, örneğin; küspe uçucu kül (Gupta, 2002), pirinç çeltiği (Masoud vd.,2012; Wang vd., 2007), kavak yaprağı tozları (Abbas, 2013), portakal kabuğu (Ali vd., 2017), şeker kamışı küspesi (Razi vd., 2018; Amin, 2008), hindistan cevizi kabuğu (Radhika ve Palanivelu, 2006), bambu (Hameed vd., 2007) ve odun talaşı (Prakash vd., 2006) gibi birçok çalışma bulunmaktadır.

Genişletilmiş yüzey alanı, mikro gözenekli yapı, yüksek adsorpsiyon kapasitesi ve yüksek derecede reaktivite, tarımsal atıklardan elde edilen aktif karbon kullanmanın avantajları arasındadır (Razi vd, 2018). Ali ve arkadaşları (2016), adsorpsiyon etkinliğinin adsorban yüzey alanına, yüzey morfolojisine ve gözenek boyutu dağılımına da bağlı olduğunu bildirmiştir.

Yapısal olarak ideal bir aktif karbonda gözenekler özel bir amaç için üretilmemiş ise $0.2-1.0 \mathrm{~cm}^{3} / \mathrm{g}$ civarında, yüzey alanı ise $400-1000$ $\mathrm{m}^{2} / \mathrm{g}$ aralı̆̆ında değişkenlik gösterebilir. Gözenek çapı ise $3 \mathrm{~A}^{0}$ ile birkaç $1000 \mathrm{~A}^{0}$ arasında değişmektedir (Morgan ve Fink, 1989; Çiftci, 2013). Omri ve Benzina (2012), badem kabuğundan elde ettikleri aktif karbonun BET yüzey alanını $893.62 \mathrm{~m}^{2} / \mathrm{g}$ ve toplam gözenek hacmini $0.472 \mathrm{~cm}^{3} / \mathrm{g}$ olarak belirlemişlerdir.

Koruyucu tekstiller hayatın her alanında çok önemli bir yere sahip olmuştur. Özellikle savunma ve biyomedikal uygulamalarda antibakteriyel ve antiviral aktiviteye sahip maddeler içeren malzemelerin geliştirilmesi oldukça geniş bir yer tutmaktadır (Zahran vd., 2014). Bu tekstil malzemelerine antimikrobiyal etki kazandırmak amacıyla çok sayıda kimyasal madde (inorganik tuzlar, organometaller, fenoller, formaldehit türevleri, antibiyotikler, aminler vb) kullanılmaktadır (Lim vd., 2014). Son yıllarda insan sağlığına ve çevreye zararı olmayan antibakteriyel ve antiviral tekstil ürünleri önem kazanmıştır. Bunların başında granüler veya toz haldeki aktif karbon, tekstil endüstrisinde en çok kullanılan adsorbanlardandır (Erkut, 2008). Aynı zamanda tekstil malzemelerine nano boyutlu metal ve metal oksitler takviye edilerek fonksiyonel özellikleri artırllabilmektedir. Özellikle toksit olmayan nano gümüş enfeksiyonları engelleme noktasında dikkat çeken antibakteriyel bir malzemedir (Rajendran vd., 2010).

Nano gümüş, özellikle antimikrobiyal özelliği ile bilinen nano-teknoloji ürünüdür. Gümüş, bakteri proteininin tiyol grupları ile etkileşerek moleküllerine bağlanmakta ve hücrenin metabolik aktivitesini sonlandırarak mikroorganizmayı tamamen yok etmektedir (Lee ve Jeong, 2005). Öte yandan gümüş partiküllerin boyutlarının küçülmesi etkin yüzey alanını artırmakta ve antibakteriyel aktiviteyi geliştirmektedir (Selvam ve Sundrarajan, 2012). Karnip ve ark. (2013), gümüş nitrat'dan kimyasal çöktürme yöntemi ile elde ettikleri gümüş nanopartiküllerinin $(\mathrm{AgNP})$ toz aktif karbona emdirme işlemi uygulamışlar ve içme sularında bulunabilen patojenik Escherichia coli'ye (E.coli) karşı antibakteriyel etkinliğini araştırmışlardır. Buna göre; aktif karbon kompozitlerinin su arıtma potansiyellerini ve gümüş emdirmenin içme suyu üretiminde etkili olduğu saptamışlardır.

El-Aassar ve ark. (2013), kimyasal çöktürme yöntemi ile farklı konsantrasyonlarda elde edilen Ag nanopartikülleri AC granüllerine emdirme işlemi uygulayarak suyun saflaştırılması için antimikrobiyal özellikleri incelenmiştir. Batch yöntemi ile temas süresinin artması ve bakteri sayısının azalmasıyla tam inhibisyonun sağlandığını, Sütun testi ile de hazırlanan AgNP/AC toz malzemenin sentetik su ve gerçek kirli su örneklerinde E.coli bakterilerinin azalttığını tespit etmişlerdir.

Nanoteknoloji ve nanopartiküller, havacılık-uzay mühendisliği, nano-elektronik, çevre iyileştirme, gibi uygulamaları ile giderek daha fazla tanınmaktadır (Gerber, ve Lang 2006). Ayrıca gümüş iyonları yara iyileştirici malzemelerde ve antibakteriyel gıda paketlerinde de sıklıkla kullanılmaktadır (Aksoy vd., 2015).

Nanopartiküller; fiziksel, kimyasal ve biyolojik olmak üzere farklı yöntemlerle sentezlenebilir. Ancak fiziksel ve kimyasal sentezleme yöntemleri hem pahalı hem de insan ve çevre sağlığı için oldukça tehlikelidir. Bu nedenle AgNP sentezi için en yaygın yöntem inorganik ajanlar tarafından kimyasal indirgeme yöntemlerdir (Antony vd., 2013).

Karbon malzemeler, karbonun kimyasal yapısından dolayı mükemmel adsorpsiyon kapasitesine sahiptir. Fakat bakteriler karbon kaynağı olarak karbonu kullanarak karbon yüzeyinde üreyebilirler. Bu sebeple karbon malzemelere antibakteriyel ajanlar bağlayarak malzemenin antibakteriyel özellikler kazandırılması sağlanır (Ma vd., 2021). 
Bu çalışmada, AgNP'ler kimyasal indirgeme yöntemi ile farklı konsantrasyonlarda hazırlandı. Elde edilen AgNP'lerin AC katkılı kumaş tarafından adsorplanabilirliği için en uygun yöntem ve parametreler belirlendi. Bu çalışmayı diğer çalışmalardan ayıran en önemli faktör ise kumaşa katkılanmış AC'nun BET yüzey alanının yaklaşık $2300 \mathrm{~m}^{2} / \mathrm{g}$ gibi çok yüksek bir değere sahip olmasıdır. Böylece elde edilen AC/AgNP takviyeli kompozit malzemenin biyolojik ve kimyasal zararlılara karşı savunmada, su arıtma filtrelerinde ağır metal giderimi ve mikrobiyal zararlılara karşı yara örtüleri gibi biyomedikal alanlarda kullanımlarının ekonomik ve çevre dostu olarak artırılması sağlanacaktır.

\section{Materyal ve Metot}

\subsection{Kullanılan Materyaller}

Gümüş nanopartikülleri hazırlamak için gümüş nitrat (\% 99,5, $\mathrm{AgNO}_{3}$, Panreac\&Applichem), Sodyum Borohidrid (\% 98, $\mathrm{NaBH}_{4}, \mathrm{FSA}$ Laboratory Supplies), Sodyum Dodesil Sülfat (\% 98, SDS) kullanıldı.

$\mathrm{Bu}$ çalışmada kullanılan aktif karbon, ipek böceği kozasından elde edilmiş olup BET (Branauer-Emmet-Teller) yüzey alanı $2353 \mathrm{~m}^{2} / \mathrm{g}$, Langmuir yüzey alanı $2749 \mathrm{~m}^{2} / \mathrm{g}$, gözenek genişliği 3-1,9 nm ve gözenek alanı $1338 \mathrm{~m}^{2} / \mathrm{g}$ olarak ölçülmüştür. Daha sonra elde edilen amorf yapılı AC, pamuklu (selüloz bazlı) kumaşa katkılanmıştır (Dilbilmez, 2019).

\subsection{AgNP'lerin Elde Edilmesi}

AgNP, Lee ve arkadaşları (2009), tarafından daha önce rapor edilmiş yöntem kullanılarak hazırlandı. Yöntem kısaca şöyledir: $0,0005 \mathrm{M}-0,002 \mathrm{M}$ aralığında farklı derişimlerde $\mathrm{AgNO}_{3}$ çözeltisi hazırlandı. Daha sonra $\mathrm{AgNO}_{3}$ derişimlerine bağlı olarak, $\mathrm{NaBH}_{4}: \mathrm{AgNO}_{3}(1: 10)$ ve $\mathrm{SDS} / \mathrm{AgNO}_{3}(1: 2)$ oranlarına göre $\mathrm{NaBH}_{4}$ ve SDS çözeltileri hazırlandı.

Kimyasal indirgeme ile AgNP elde edilmesi için ilk olarak $\mathrm{NaBH}_{4}$ çözeltisi içerisine stabilizör (SDS) eklenerek bir stabilizatör çözeltisi elde edildi. Daha sonra elde edilen bu çözelti üzerine $\mathrm{AgNO}_{3}$ çözeltisi damla damla eklendi ve bir saat boyunca karıştırıldı.

$\mathrm{Bu}$ işlem farklı derişimdeki $\mathrm{AgNO}_{3}$ çözeltileri de kullanılarak gerçekleştirildi. AgNP oluşumu, UV-VIS (Evolutıon 600) spektrofotometre ile, partikül büyüklüğü ve partikül dağılımlarının belirlenmesi ise ZetaSizer (Malvern Instruments Nano ZS, Malvern, UK) yardımıyla belirlendi.

\subsection{AC Katkılı Kumaş/AgNP Takviyesi}

AgNP'lerin AC katkılı kumaşa adsorpsiyon yolu ile takviyesi için 3 farklı yöntem uygulanmıştır. Bunlar;

Yöntem 1: Ultrasonik Banyo (UB) içerisindeki çözelti içerisinde bekletme,

Yöntem 2: Manyetik Karıştırıcı üzerinde 20 rpm karıştırma hızındaki çözelti içerisinde bekletme,

Yöntem 3: Hiçbir dış etkene maruz bırakılmadan çözelti içerisine bırakılarak bekletme.

Her 3 yöntem için $1 \mathrm{x} 1 \mathrm{~cm}$ boyutunda saf kumaş ve AC katkılı kumaş numuneler farklı derişimlerdeki AgNP çözeltileri içerisinde $15 \mathrm{dk}$, $30 \mathrm{dk}, 1 \mathrm{sa}, 2 \mathrm{sa}$, 4sa, $8 \mathrm{sa}, 16 \mathrm{sa}$ ve $24 \mathrm{sa}$ bekletilerek, vakumlu etüvde 4 inchHg basınçta, $50{ }^{\circ} \mathrm{C}$ 'de 24 saat kurutulmuştur. Daha sonra yüzeysel yapı analizi ve nanopartikül dağılımları Taramalı Elektron Mikroskobu (SEM, JEOL JSM 5600) ile, adsorplanmış AgNP miktarları ise İndüktif Eşleşmiş Plazma Optik Emisyon Spektroskopi (ICP-OES, Perkin Elmer) kullanılarak belirlendi.

\section{Bulgular ve Tartışma}

\subsection{AgNP Sentezinin Optimizasyonu}

Kimyasal indirgeme yöntemi ile edilen farklı başlangıç $\mathrm{AgNO}_{3}$ konsantrasyonlarına (0,0005M, 0,001M ve 0,002M) sahip kolloidal AgNP'ler Şekil 1'de görüldüğü gibi çözeltilerin rengi başlangıç konsantrasyonunun arttırılmasıyla sarıdan kahverengiye değişmiştir.

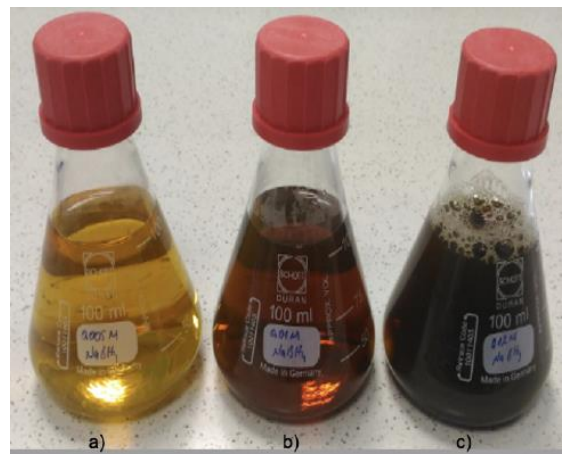

Şekil 1. $\mathrm{AgNO}_{3}$ konsantrasyonun etkisi: (a) 0,0005 M (b) 0,001 M (c) 0,002 M 
Aşağıdaki reaksiyon sonucunda $\mathrm{NaBH}_{4}$ 'ün hidrolizi yoluyla üretilen bor hidroksitin yüzeyin elektron yoğunluğunu azaltarak AgNP'lerin oluşmasına ve derinde toplanmasına neden olur (Liu vd., 2007).

$$
\mathrm{Ag}^{+}+\mathrm{BH}_{4}{ }^{-}+3 \mathrm{H}_{2} \mathrm{O} \rightarrow \mathrm{Ag}^{0}+\mathrm{B}(\mathrm{OH})_{3}+3,5 \mathrm{H}_{2}
$$

AgNP'lerin UV-VIS spektrumlarının $400 \mathrm{~nm}$ 'de emilim ve soğurma piki verdiği ve emilim pikinin tepe noktası ne kadar dar olursa nanopartiküllerin yayılmasının da o derece iyi olacağı bilinmektedir (Kim vd., 2004).

$\mathrm{Bu}$ çalışma için hazırlamış olduğumuz 3 farklı $\mathrm{AgNO}_{3}$ konsantrasyonuna sahip çözeltilerin Zeta Potansiyel test sonuçları Tablo 1'de, UV-VIS spektrumları ise Şekil 2'de gösterilmiştir.

Zeta potansiyeli genellikle $+30 \mathrm{mV}$ değerinden daha pozitif veya $-30 \mathrm{mV}$ değerinden daha negatif olması istenir. Tane boyutu küçüldükçe negatif yüzey yükleri artar ve zeta potansiyel negatif değer alır (Çanayaz, 2016). Tablo 1'de verilen sonuçlara göre 0,0005M konsantrasyonlu çözelti içerisindeki AgNP'lerin istenilen homojenlikte dağılım sergilediği, 0,001M ve 0,002M konsantrasyonlu çözeltilerde ise artan konsantrasyonla homojenliğin kaybolduğu ve kararlı bir yapıdan uzaklaşıldığı gözlenmiştir.

Tablo 1. Kollaidal AgNP çözeltilerinin Zeta Potansiyel ve tane boyutları

\begin{tabular}{cccc}
\hline $\begin{array}{c}\text { Numune } \\
\text { Nu. }\end{array}$ & $\begin{array}{c}\text { Cözelti İçerisindeki AgNO } \\
\text { Konsantrasyonu }\end{array}$ & $\begin{array}{c}\text { Zeta Potansiyel } \\
(\mathbf{m V})\end{array}$ & Tane Boyutu (d.nm) \\
\hline 1 & $0,0005 \mathrm{M}$ & $-40,0$ & 31,04 \\
2 & $0,001 \mathrm{M}$ & $-28,4$ & 19,66 \\
3 & $0,002 \mathrm{M}$ & $-14,8$ & 18,05 \\
\hline
\end{tabular}

Šıleıkaıtė ve arkadaşları (2009), gümüş nitratı sodyum sitrat ile indirgeyerek oluşturdukları AgNP'lerin SEM analizi ile $45 \mathrm{~nm}$ - $50 \mathrm{~nm}$ aralığında küresel nanopartiküller elde etmişler ve sentez aşamalarında farklı boyutlarda nanopartiküller elde edilebileceğini söylemişlerdir.

UV-VIS spektrum sonuçları incelendiğinde ise; $\mathrm{AgNO}_{3}$ konsantrasyonu arttırıldığında emilim pik yoğunluğunun zirvelerde dağılarak arttığı, soğurma pikinin genişlediği ve nanopartiküllerin kümelenemediği görüldü. Ancak düşük konsantrasyonda daha dar bir emilim zirvesi elde edilmesi düşük konsantrasyonda nanopartiküllerin daha iyi dağılmış ve kümelenmiş olduğunu doğrulamaktadır.

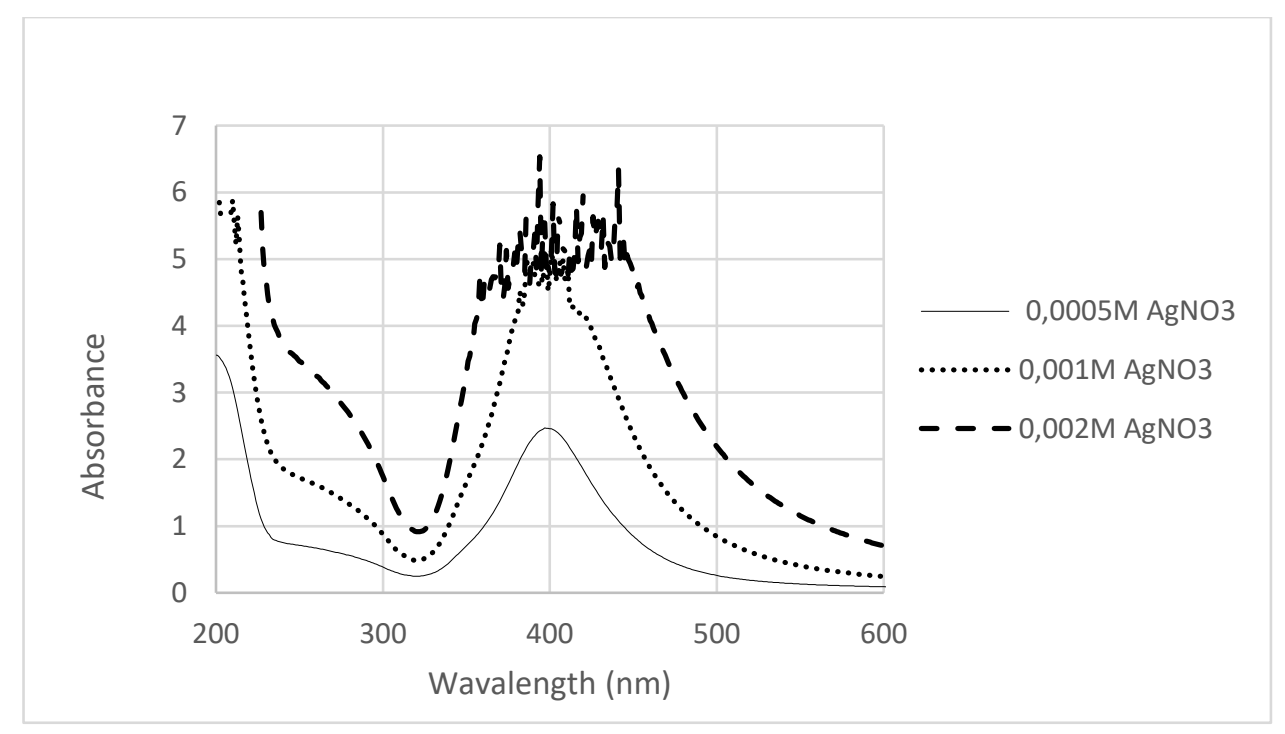

Şekil 3. Kolloidal AgNP Çözeltilerinin UV-VIS Spektrofotometre Sonuçları

Az miktarda $\mathrm{NaBH}_{4}$ kullanıldığında, çok ince $\mathrm{BH}_{4}$ tabakası bor hidroksitin yüzey emilimini ve elektron yoğunluğunu arttırarak AgNP'lerin kümelenmesine neden olur. Buda $\mathrm{NaBH}_{4}$ 'ün sadece indirgeyici bir ajan olarak değil aynı zamanda gümüş nanoparçacıkların kümelenmesini de önleyen bir dengeleyici olduğunu gösterir. Ayrıca SDS'nin çözeltide kullanılmasının temel amacı, büyüme ve kümelenmeden kaynaklanan AgNP'lerin kolloidal bir halde çözelti içerisinde kalmasını sağlamaktır (Lee vd., 2009). Yine Şekil 2'den de anlaşılacağı gibi konsantrasyon arttırılıp SDS oranı sabit kaldığında soğurma tepelerinin dağıldı̆̆ı, $\mathrm{SDS} / \mathrm{AgNO}_{3}$ ağırlık oranının $\mathrm{AgNO}_{3}$ 'ün düşük konsantrasyonunda AgNP'leri soğurma tepelerinde bir araya topladığı ve iyi bir şekilde dağıttığını göstermiştir. 


\subsection{AC Katkılı Kumaş/AgNP Adsorpsiyon Analizleri}

İndüktif Eşleşmiş Plazma Optik Emisyon Spektroskopi (ICP-OES); kimyasal elementlerin tespiti için kullanılan analitik bir tekniktir (Bakırdere vd., 2011). AgNP'lerin AC katkılı kumaşa takviyesi için en uygun 3 farklı bekletme yöntem ve süresinin belirlenebilmesi için ICP-OES testi yapılmıştır.

AC katkılı kumaş numunesinin UB içerisinde bekletme sonrası AgNP adsorbans miktarları, farklı bekletme süreleri Tablo 2'de verilmiştir. Buna göre 3, 4 ve 5 nolu numunelerde sirasiyla $0,454 \pm 0,005,0,450 \pm 0,002$ ve $0,450 \pm 0,003 \mathrm{mg} / \mathrm{kg}$ olduğu ve AgNP miktarının çok fazla değiş̧mediği görülmektedir. Bu nedenle AC katkılı kumaşın uzun süre bekletmenin adsorpsiyon verimini artmasına pozitif yönde bir katkı sağlamadığını söyleyebilir. Sonuç olarak, çözelti içerisinde en uygun bekletme süresinin 1 saat olduğu belirlenmiştir.

AC katkılı ve saf kumaş numunelerine uygulanan farklı bekletme yöntemleri sonucunda elde edilen AgNP miktarları (ICP-OES) ise Tablo 3'de verilmiştir. AC'li kumaşı AgNP miktarlarının tüm yöntemlerde saf kumaşa göre daha yüksek olduğu görülmektedir. Bu da aktif karbonun yüksek yüzey alana ve organik bileşenlerinin yüksek absorplama kapasitesine sahip olmasından kaynaklıdır. Kullanılan bekletme yöntemleri kıyaslandığında ise en yüksek AgNP miktarının ultrasonik banyo ile gerçekleştiği saptanmıştır. Magnetik karıştırıcı yöntemi ile kumaş üzerinde bulunan aktif karbon parçacıklarının bir miktar dökülmesine sebep olmasıyla takviye eleman miktarının azalmasına sebep olmuştur.

Ma ve arkadaşları (2021), karbon kaynağı olarak bakteriyel selüloz kullanılarak AgNP'li antibakteriyel karbonize selüloz (CBC) kompozit üretmişlerdir. CBC'nin AgNP miktarı, yüzeyi ve gözenek yapısınınAgNO 3 çözeltisinin başlangıç konsantrasyonuna bağlı olduğunu saptamışlardır. Ayrıca, Ag/CBC kompozitinin mükemmel antibakteriyel aktivite sergilediğini tespit etmişlerdir.

Tablo 2. UB İçerisinde Bekletilmiş AC Kumaş Numunelerinin ICP-OES Test Analizi

\begin{tabular}{|c|c|c|c|}
\hline $\begin{array}{l}\text { Numune } \\
\text { Nu. }\end{array}$ & $\begin{array}{c}\text { UB İçerisinde } \\
\text { Bekleme Süresi }\end{array}$ & $\begin{array}{c}\text { Adsorplanmıs } \\
\text { Ag }^{+} \text {Miktarı (mg/kg) }\end{array}$ & $\begin{array}{l}\text { Con SD } \\
(\mathrm{mg} / \mathrm{kg})\end{array}$ \\
\hline 1 & 15 Dakika & 0,101 & $\pm 0,020$ \\
\hline 2 & 30 Dakika & 0,328 & $\pm 0,090$ \\
\hline 3 & 1 Saat & 0,454 & $\pm 0,005$ \\
\hline 4 & 2 Saat & 0,450 & $\pm 0,002$ \\
\hline 5 & 4 Saat & 0,450 & $\pm 0,003$ \\
\hline 6 & 8 Saat & 0,112 & $\pm 0,040$ \\
\hline 7 & 16 Saat & 0,191 & $\pm 0,020$ \\
\hline 8 & 24 Saat & 0,184 & $\pm 0,020$ \\
\hline
\end{tabular}

Tablo 3. Bekletme Yöntemleri ile Kumaş Numunelerinin ICP-OES Test Analizi

\begin{tabular}{cccccc}
\hline Numune & Yöntem & $\begin{array}{c}\text { Numune } \\
\text { Türü }\end{array}$ & $\begin{array}{c}\text { Bekletilme } \\
\text { Süresi }\end{array}$ & $\begin{array}{c}\text { Adsorplanmış } \\
\text { Ag+ Miktarı } \\
(\mathbf{m g} / \mathbf{k g})\end{array}$ & $\begin{array}{c}\text { Con SD } \\
(\mathbf{m g} / \mathbf{k g})\end{array}$ \\
\hline 1 & Bekletme & Saf kumaş & & 0,051 & 0,002 \\
2 & Bekletme & AC'li & & 0,051 & 0,008 \\
3 & Ultrasonik Banyo & Saf Kumaş & \multirow{2}{*}{1 saat } & 0,190 & 0,002 \\
$\mathbf{4}$ & Ultrasonik Banyo & AC'li & & $\mathbf{0 , 6 0 3}$ & $\mathbf{0 , 0 0 3}$ \\
5 & Magnetik Karıştırıc1 & Saf Kumaş & & 0,332 & 0,002 \\
6 & Magnetik Karıştırıc1 & AC'li & 0,345 & 0,002 \\
\hline
\end{tabular}

AC katkılı ve saf kumaşın SEM görüntüleri Şekil 4 (a,b) ile UB içerisindeki çözelti içerisinde 1 saat bekletilerek AgNP takviyeli kompozit malzemenin SEM-EDS analiz sonuçları Şekil 4(c,d)'de verilmiştir. 

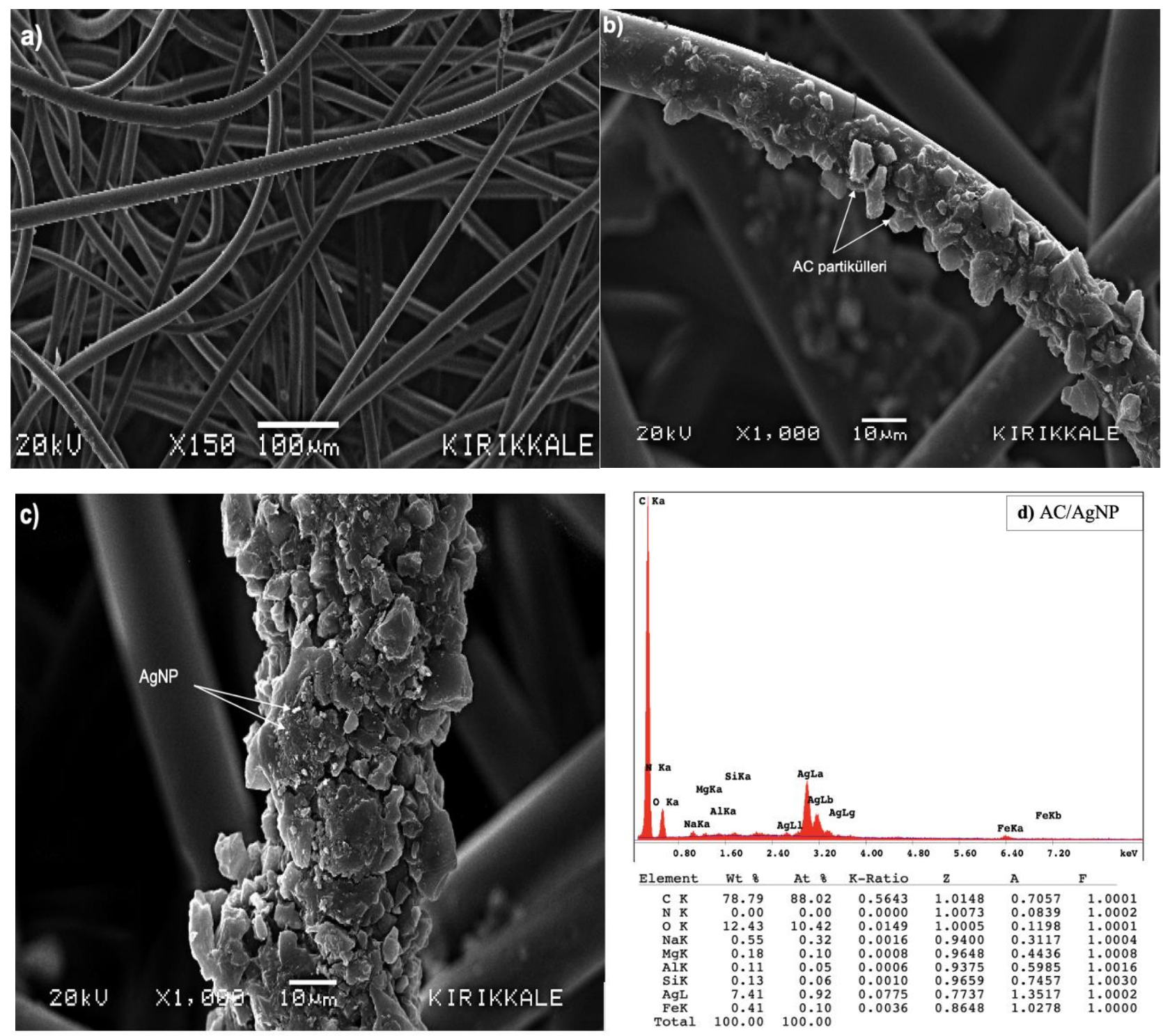

Şekil 4. UB içerisinde (0,0005 M konsantrasyonlu çözelti) 1saat bekletme sonrası (a) Saf kumaş (b) AC katkılı (c) AC/AgNP katkılı kumaşın SEM görüntüleri (d) AC/AgNP EDS spektrum verileri

Çakar ve ark. (2015), pamuklu kumaşlara korono plazma ile AgNP ve çinko oksit nano partikülleri (ZnO-NP) takviye ederek yıkanmaya karşı yıpranmasını araştırmışlar ve gram pozitif Staphylococcus aureus (S.aureus) bakterisine karşı etkiye sahip olduğunu göstermişlerdir. Bakar ve ark. (2021), muz kabuğundan elde edilen aktif karbonu atık-su filtre kumaşlarına adsorpsiyonu ile içme sularındaki ağır metallerin uzaklaştııılması hakkında araştırma çalışması yapmışlar ve $\mathrm{Cd}^{+2}, \mathrm{Ni}^{+2}, \mathrm{Cu}^{+2}, \mathrm{~Pb}^{+2}$ ve $\mathrm{Zn}^{+2}$ ağır metallerin uzaklaştırılması için kullanılan adsorbanın yüksek gözeneklilik ve yüzey alanı ile hazırlanması gerektiğini saptamışlardır.

\section{Sonuçlar}

Bu çalışmada, uygun bir indirgeyici olan Sodyum borohidrid ve dengeleyici olarak Sodyum Dodosil Sülfat varlığında Gümüş Nitrat konsantrasyonu azaltılarak kararlı gümüş nanopartikülleri elde etmek için uygun bir çözelti başarıyla hazırlandı. Elde edilen çözeltinin Zeta Potansiyeli AgNP'erin istenilen homojenlikte dağılım sergilediğini, UV-VIS spektrumları ise Gümüş Nitratın azalan konsantrasyonuyla nanopartiküllerin daha iyi dağılmış ve kümelenmiş olduğunu doğruladı. Buna göre 0,0005M konsantrasyonlu $\mathrm{AgNO}_{3}$ çözeltisinden d(nm) 31,04 nm tane boyutlu AgNP elde edilmiştir.

Elde edilen AgNP'lerin AC Katkııı Kumaş tarafından adsorplanması için çözelti içerisinde en ideal bekleme süresi ve bekleme yöntemi belirlendi. Buna göre ultrasonik banyoda 1 saat bekletme AgNP'lerin AC katkılı kumaş yüzeyleri tarafından başarıyla adsorplandığı SEM görüntüleri ile, nanopartiküllerin yüzeydeki miktarsal varlığı ise ICP-OES test cihazları ile doğrulandı. 
AC katkılı kumaş üzerine kaplanan gümüş nanoparçacıkların miktarını belirleyen en önemli etkenlerin; AgNP çözelti konsantrasyonu, adsorplama yöntemi ve bekletilme süresi olduğu belirlenmiştir. Kullanılan AC'lu kumaşın çok yüksek yüzey alanı ve gözenek yapısı AgNP'lerin adsorplanmasındaki etkisi bu çalışmanın en önemli sonuçlarındandır.

\section{Teşekkür}

Bu çalışmada kullanılan aktif karbon kaplı kumaşı üreten Muğla Sıtkı Koçman Üniversitesi öğretim üyesi Prof. Dr. Selçuk Aktürk’e teşekkürlerimizi borç biliriz.

\section{Referanslar}

Abbas, F. S. (2017). Dyes removal from wastewater using agricultural waste. Adv. Environ. Biol. 7 (6), 1019-1026, 2013.

Aksoy S., A., Çakar A., Korkmaz N. (2015). Korona Plazma ile Aktive Edilmiş Pamuklu Kumaşa Gümüş ve Çinko Oksit Nanopartikül Aplikasyonu, Süleyman Demirel Üniversitesi Fen Bilimleri Enstitüsü Dergisi, 19 (2), 78-85.

Ali, H.H, Abdel-Satar, Amaal M. (2017). Removal of some heavy metals from aqueous solutions using natural wastes orange peel activated carbon. J. Appl. Sci. 3 (3), 13-30.

Ali A., Saeed K., Mabood F. (2016). Removal of chromium (VI) from aqueous medium using chemically modified banana peels as efficient low-cost adsorbent. Alexandria Eng. J. 55 (3), 2933-2942.

Amin N. K. (2008). Removal of reactive dye from aqueous solutions by adsorption onto activated carbons prepared from sugar-cane bagasse pith, Desalination 223, 152-161.

Antony J. J., Nivedheetha M., Siva D., Pradeepha G., Kokilavani P., Kalaiselvi S., Sankarganesh A., Balasundaram A., Masilamani V., Achiraman S. (2013). Antimicrobial Activity of Leucas Aspera Engineered Silver Nanoparticles Against Aeromonas Hydrophila in İnfected Catla Catla. Colloids and Surfaces B: Biointerfaces, 109: 20-24.

Bakar N. A., Othman N., Yunus Z. M., Altowayti W. A. H., Tahir M., Fitriani N., Mohd-Salleh S. N. A. (2021). An insight review of lignocellulosic materials as activated carbon precursor for textile wastewater treatment, Environmental Technology \& Innovation 22, 101445.

Bakirdere, S., Aydin, F., Bakirdere, E. G., Titretir, S. (2011). Akdeniz, İ., Aydin, I., Yildirim, E., Arslan, Y., From mg/kg to pg/kg levels: a story of trace element determination: a review. Applied Spectroscopy Reviews, 46: 38-66.

Baytar., O. (2015). İğde Çekirdeği ve Kayın Ağacından Üretilen Aktif Karbonun Ağır Metal Ve Boyarmadde Gideriminde Kullanılması., Doktora Tezi., Selçuk Üniversitesi Fen Bilimleri Enstitüsü., Konya.

Çakar A., Aksoy s. A., Korkmaz N. (2015). Korona Plazma ile Aktive Edilmiş Pamuklu Kumaşa Gümüş ve Çinko Oksit Nano Partikül Aplikasyonu, Suleyman Demirel University Journal of Natural and Applied Science, 19(2), 78-85.

Çanayaz Y. (2016), Farklı İyonik Çevrelerde Membranların Yüzey İletkenliğinin Zeta Potansiyeli Üzerine Ektileri, Yüksek Lisans, Cumhuriyet Üniversitesi Fen Bilimleri Enstitüsü, Sivas.

Çiftçi H. (2013). Aktif Karbonla Topraktan Tuz Adsorpsiyonu Yolu İle Tuzlanmış Tarım Arazilerinin Islah Edilebileceğinin Araştırılması, Yüksek Lisans, Harran Üniversitesi Fen Bilimleri Enstitüsü Şanlıurfa.

Dilbilmez S. G. (2019). KBRN (Kimyasal, Biyolojik, Radyasyon, Nükleer) Tehditlere Karşı Koruyucu Malzemelerin Geliştirilmesi, Yüksek Lisans, Muğla Sitkı Koçman Üniversitesi, Fen Bilimleri Enstitüsü, Muğla.

El-Aassar A. H. M., Said M. M., Abdel-Gawad A. M., Shawky H. A. (2013). Using Silver Nanoparticles Coated on Activated Carbon Granules in Columns for Microbiological Pollutants Water Disinfection in Abu Rawash area, Great Cairo, Egypt, Australian Journal of Basic and Applied Sciences, 7(1): 422-432.

Erkut, E. (2008). Aktif Karbon Adsorpsiyonu ile Boyarmadde Giderimi, Yüksek Lisans Tezi, Anadolu Üniversitesi, Fen Bilimleri Enstitüsü, Eskişehir, Türkiye, 39-71.

Gerber C, Lang HP. (2006). How the doors to the nano-world were opened. Nature Nanotechnology, 1 (1): 3.

Gupta, Vinod K., Jain, C.K., Ali, Imran, Chandra, S., Agarwal, S. (2002). Removal of lindane and malathion from wastewater using bagasse fly ash - A sugar industry waste. Water Res. 36 (10), 2483-2490. 
Hameed B.H., Din A.T.M., Ahmad A.L. (2007). Adsorption of meth- ylene blue onto bamboo-based activated carbon: Kinetics and equilibrium studies, J. Hazard. Mater. 141, 819-825.

Karnib M., Holail H., Olama Z., Kabbani A., Hines M. (2013).The Antibacterial Activity of Activated Carbon, Silver, Silver Impregnated Activated Carbon and Silica Sand Nanoparticles against Pathogenic E. coli BL21, Int.J.Curr.Microbiol.App.Sci., 2(4): 20-30.

Kim K. D., Han D. N. and Kim H. T. (2004). Chem. Engin. J., 104, 55.

Küçükgül E. Y. (2004). Productıon Of The Commerıcal Actıvated Carbon And Determınatıon Of The Propertıes, Deü Mühendislik Fakültesi Fen Ve Mühendislik Dergisi, 6 (3), 41-56.

Lee., B., S., Song., K., C., Lee.,S., M., Park., S., T. (2009). Preparation of colloidal silver nanoparticles by chemical reduction method, Korean J. Chem. Eng., 26 (1), 153-155.

Lee J., Jeong S. (2005). Bacteriostasis and Skin Innoxiousness of Nanosize Silver Colloids on Textile Fabrics. Textile Research Journal, $75,551-556$.

Lim S., H., Hudson, S., M. (2004). Application of a Fiber- Reactive Chitosan Derivative to Cotton Fabric as an Antimicrobial Textile Finish. Carbohydrate Polymers, 56, 227-234.

Liu J., Lee J. B., Kim D. H., Kim Y. (2007). Colloids Surf. A, 302, 276.

Ma B., Chaudhary J. P., Zhu J., Sun B., Chen C., Sun D. (2021). Construction of silver nanoparticles anchored in carbonized bacterial cellulose with enhanced antibacterial properties, Colloids and Surfaces A: Physicochemical and Engineering Aspects 611, 125845.

Masoud, Mamdouh S., El-Saraf, Wagdi M., Abdel-Halim, Ahmed M., Ali, Alaa E., Mohamed, Essam A., Hasan, Hamad M.I. (2012). Rice husk and activated carbon for waste water treatment of El-Mex Bay, Alexandria Coast, Egypt. Arab. J. Chem. 1-8.

Morgan I., Fink C. E. (1989). “Activated Carbon Production”, Chem. Ind. Eng. 2, 219 Norit (1983): “Activated Carbon” Main Grades of Norit Activated Carbon and their Applications, Amersfoort, The Netherlands.

Omri A., Mourad Benzina M. (2012). Adsorption characteristics of silver ions onto activated carbon prepared from almond Shell, Desalination and Water Treatment, 5(10-12), 2317-2326.

Prakash Kumar B.G., Shivakamy K., Miranda L. R., Velan M. (2006). Preparation of steam activated carbon from rubber- wood sawdust (Hevea brasiliensis) and its adsorption kinetics, J. Hazard. Mater. B136, 922-929.

Radhika M., Palanivelu K. (2006). Adsorptive removal of chlorophe- nols from aqueous solution by low cost adsorbent-kinetics and isotherm analysis, J. Hazard. Mater. B138 116-124.

Rajendran R., Balakumar C., Mohammed A. H. A., Jayakumar S., Vaideki K., Rajesh E., M. (2010). Use of Zinc Oxide Nano Particles For Production of Antimicrobial Textiles. International Journal of Engineering Science and Technology, 2(1), 202-208.

Razi, Mohd Adib Mohammad, Al-Gheethi, Adel, Izzatul Ashikin, Z.A. (2018). Removal of heavy metals from textile wastewater using sugarcane bagasse activated carbon. Int. J. Eng. Technol. 7 (4.30), 112-115.

Selvam S., Sundrarajan M. (2012). Functionalization of Cotton Fabric with PVP/ZnO Nanoparticles for Improved Reactive Dyeability and Antibacterial Activity. Carbohydrate Polymers, 87,1419-1424.

Šıleıkaıtė A., Puı̌̌o J, Prosyčevas I., Tamulevıčıus S. (2009). Investigation Of Silver Nanoparticles Formation Kinetics During Reduction Of Silver Nitrate With Sodium Citrate, Materials Science (Medžlagotyra). Vol. 15, No. 1.

Yahya, M.A., Al-Qodah, Z., Ngah, C.Z. (2015). Agricultural bio-waste materials as potential sustainable precursors used for activated carbon production: A review. Renew. Sustain. Energy Rev. 46, 218-235.

Zahran M.K., Ahmed H.B.; El-Rafie M. H. (2014). Carbohydrate Polymers, 108, 145-152.

Wang S.L., Tzou Y.M., Lu Y.H., Sheng G. (2007). Removal of 3-chlo- rophenol from water using rice-straw-based carbon, J. Hazard. Mater. 147 313-318. 